\begin{tabular}{|l|l|l||}
\hline \multicolumn{2}{|c|}{ PublisherInfo } \\
\hline \hline PublisherName & $:$ & BioMed Central \\
\hline \hline PublisherLocation & $:$ & London \\
\hline \hline PublisherImprintName & $:$ & BioMed Central \\
\hline \hline
\end{tabular}

\title{
Picturing gene expression in the brain
}

\begin{tabular}{|l|l|l||}
\hline \multicolumn{2}{|c|}{ ArticleInfo } \\
\hline \hline ArticleID & $:$ & 4337 \\
\hline \hline ArticleDOI & $:$ & $10.1186 /$ gb-2002-3-5-reports0025 \\
\hline \hline ArticleCitationID & $:$ & reports0025 \\
\hline \hline ArticleSequenceNumber & $:$ & 19 \\
\hline \hline ArticleCategory & $:$ & Paper report \\
\hline \hline ArticleFirstPage & $:$ & 1 \\
\hline \hline ArticleLastPage & $:$ & 4 \\
\hline \hline & & RegistrationDate : 2002-2-25 \\
ArticleHistory & $:$ & Received \\
& & OnlineDate 2002-2-25 \\
\hline \hline ArticleCopyright & $:$ & BioMed Central Ltd2002-5-2 \\
\hline \hline ArticleGrants & $:$ & \\
\hline \hline
\end{tabular}




\begin{tabular}{|l|l|l||}
\hline ArticleContext & $:$ & 130593355 \\
\hline
\end{tabular}

\section{Agnieszka M Lichanska}

\section{Abstract}

Voxelation is used as a novel method for three-dimensional imaging of gene expression in the brain

\section{Significance and context}

The brain is a very complex organ, containing various cell types, many millions of neurons and billions of interconnections. The obvious question is: how does gene expression generate such a complex three-dimensional structure? Current methods for analyzing gene expression are quite inadequate to address this question, as most methods, such as in situ hybridization of brain sections, give only two-dimensional spatial patterns of expression. Microarray analysis, on the other hand, has been used mainly to study temporal changes in gene expression. Brown et al. present a new approach to correlating microarray data with the site of gene expression in tissues, by creating signatures of expression patterns in coronal hemisections at the level of the hippocampus of the human brain. By combining the data for the entire surface of a volume of a brain section they can generate a threedimensional spatial pattern of gene expression. The authors applied this new method to analysis of Alzheimer's and normal tissue samples obtained post mortem from people with and without the brainrelated illness.

\section{Key results}

An important part of the results is the validation of the reproducibility of the method. By applying a microarray analysis of 5,000 genes to four individual samples of a single voxel (small cube) and using scatter-plots to analyze the results, the authors show excellent reproducibility of the results between individual samples. At the same time, the statistical analysis of the results from voxels using the smaller 2,000-gene array also revealed high reproducibility between and within the hemisections. The results illustrate the differences between gene expression in normal brain compared with brain affected by Alzheimer's disease. Analysis of the microarray data has identified two clusters of genes co-regulated in the two samples. Each cluster was positively correlated with itself and negatively correlated with the other cluster: for example, the genes $U 5-100 \mathrm{~K}$ from cluster 1 and $R N P S 1$ from cluster 2 have highly negatively correlated spatial expression patterns. It was suggested that this might be explained by similar functions of these proteins. 
The comparison between normal and Alzheimer's brain revealed 34 differentially expressed genes. These included eight transcription-associated genes (for example, $D R A P 1$ and $T A F 2 F$ ), five involved in signal transduction (for example, $R A P 2 A$ and $P R K C B 1$ ), three involved in modulating the cytoskeleton (for example, ICAAP-1A), two in respiration (for example, $C O X 7 B$ ), two in redox reactions (for example, $C C S$ ), twelve unclassified genes (for example, LIMS1 and RAB2) and two novel genes. Singular value decomposition (SVD) analysis of the top 120 differentially expressed genes allowed identification of genes expressed specifically in cortex, caudate, hippocampus, and insular cortex. An exhaustive analysis of the non-coding regions of the correlated and anticorrelated genes was used to identify and compare the regulatory sequences. This analysis confirmed the presence of known regulatory sites.

\section{Methodological innovations}

Horizontal sections (hemisections) were divided into 24 voxels (small cubes). Some voxels were empty as a result of the difference between brain shape and the voxel grid. All voxels containing $50 \%$ biological material by volume were pooled with the neighboring voxels for analysis. Gene expression in each voxel was then analyzed using a 2,000 gene microarray, with RNA from the total hemisection as a control. Matrices correlating gene expression levels to the arbitrary scales were generated from the array data. These were used to identify genes co-expressed or differentially expressed between normal and diseased tissue. The microarray data were statistically analyzed using SVD analysis. This enabled the generation of regional maps of gene expression by sequential analysis (principal component analysis) of the expression patterns and correlation of gene expression with anatomical area.

\section{Links}

More information on the work is available from the Smith Lab website and Supplementary data to Genome Research 12:244-254 are available.

\section{Conclusions}

Brown et al. conclude that voxelation is a useful method for understanding how the three-dimensional structure of the brain develops. It is also the first step towards expression mapping of complex organs.

\section{Reporter's comments}


This method is revolutionary. By analyzing sufficient brain sections it is possible to obtain a full three-dimensional picture of gene expression in the brain. The method has an advantage over total brain microarray analysis as it allows identification of genes that are expressed at low level. The authors point out that higher-resolution voxelation maps will be more informative, but the technology has to improve before that is possible. These types of maps can also be applied to other tissues. For the analysis of diseased versus healthy brain, however, the use of age-matched controls is a better option than using significantly younger controls as there is then no possibility of skewed results as a result of lower gene expression resulting from a combination of disease and neuronal cell death resulting from age-related changes.

\section{Table of links}

Genome Research

Smith Lab website

Supplementary data to Genome Research 12:244-254

\section{References}

1. Brown VM, Ossadtchi A, Khan AH, Cherry SR, Leahy RM, Smith DJ: High throughput imaging of brain gene expression. Genome Res. 2002, 12: 244-254. 1088-9051 